\title{
CALCANEAL ARTICULAR FACET CONFIGURATION TYPES: A REPORT OF A CADAVERIC STUDY AND THE CALCANEAL CONSTRICTION INDEX
}

\section{Patrick Anderson McShane.}

Private practice, podiatric medicine, 1834 South Stewart Avenue, Springfield, Missouri, USA.

\section{ABSTRACT}

Background: The superior surface of the calcaneus will frequently demonstrate 3 articular facets for the articulation with the talus: anterior, middle, and posterior. There are several possible configurations of these articular facets. The present article is a reporting of a cadaveric study of facets on the superior calcaneal surface as well as a literature review of current classification schemes of calcaneal facets. The Calcaneal Constriction Index is introduced as a better measuring method for classification of the non-constricted and constricted types of fused calcaneal middle and anterior facets.

Results: Of 158 total cadaveric specimens, there were seven types of calcanei observed. Using the Calcaneal Constriction Index for measurement of fused Type 1A non-constricted and Type 1B constricted yielded 21 specimens and 29 specimens, respectively. In Type $2 \mathrm{~A}$ there were 18, Type $2 \mathrm{~B}$ had 40 . Type 2C had 39 specimens included and in Type 2D there were 3 specimens found. For Type 3, anterior facets were absent in 8 specimens.

Conclusions: For assigning the Type $1 \mathrm{~A}$ and Type $1 \mathrm{~B}$ into their proper calcaneal configuration categories, the Calcaneal Constriction Index is shown to provide a simple, intuitive, reproduceable and easily measurable method for the fused middle and anterior type of calcaneal facets. Review of the literature shows that there is a need to establish a consensus between future authors in naming of the types of articular facets on the superior aspect of the calcaneus.

Key Words: calcaneus, variations, anterior facet, constricted, non-constricted, fused, calcaneal facets, subtalar joint, articular facets, absent anterior facet

Corresponding Author: Patrick Anderson McShane, DPM (Doctor of Podiatric Medicine), Private practice, podiatric medicine, 1834 South Stewart Avenue, Springfield, Missouri, USA.65804.

E-Mail: pmdlm@sbcglobal.net

Access this Article online

Quick Response code

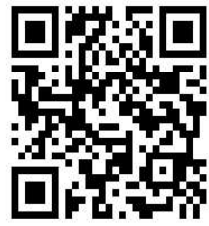

DOI: $10.16965 /$ ijar.2020.199

Journal Information

International Journal of Anatomy and Research

RG Journal ISSN (E) 2321-4287 | ISSN (P) 2321-8967

Impact: 0.21* https://www.ijmhr.org/ijar.htm

DOI-Prefix: https://dx.doi.org/10.16965/ijar

\section{Article Information}

Received: 28 Jul 2020

Peer Review: 29 Jul 2020

Revised: None
Accepted: 26 Aug 2020

Published (O): 10 Sep 2020

Published (P): 10 Sep 2020

\section{INTRODUCTION}

The calcaneus is the largest bone of the human foot. The articular surfaces between the calcaneus and the talus in the foot establish the subtalar joint, which is mostly responsible for inversion and eversion of the foot. All calcanei demonstrate posterior and middle facets. Most (but not all) calcanei possess an anterior facet. The configuration of the facets of the superior aspect of the calcaneus have been categorized by various authors into groups based on 1) whether the anterior and middle facets are fused or separate and 2) whether the anterior facet is missing/absent and 3) whether the posterior facet is fused or separate from the middle facet. There is contradicting evidence within the literature to support a consensus on the naming of calcaneal facet configurations.

After studying several various category schemes of many authors reporting on the calcaneal facet 
configurations, this study will use a classification scheme modified from the lamsaard [1] article (Figure 1):
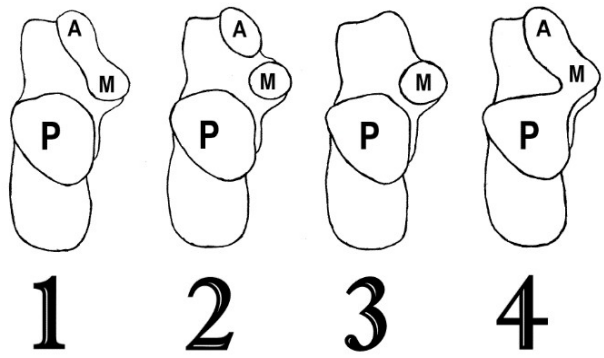

Fig. 1: Dorsal calcaneus demonstrating the four configurations of calcaneal facets used in this study. $\mathrm{P}=$ posterior facet, $\mathrm{M}=$ middle facet, $\mathrm{A}=$ anterior facet. $1=$ fused $M$ and $A, 2=$ separate $M$ and $A, 3=$ absent $A$, $4=$ fused $P$ and $M$. See text.

Type 1: the middle and anterior Calcaneal facets are fused. Type 2: the middle and anterior facets are separate. Type 3: the anterior facet is absent. Type 4 is defined as: the posterior and middle facets are fused, with or without fusion of the anterior facet.

Regarding types 1 and 2, two subtypes for Type 1 (fused middle and anterior facets) are recognized and four subtypes for Type 2 (separate middle and anterior facets) are recognized.

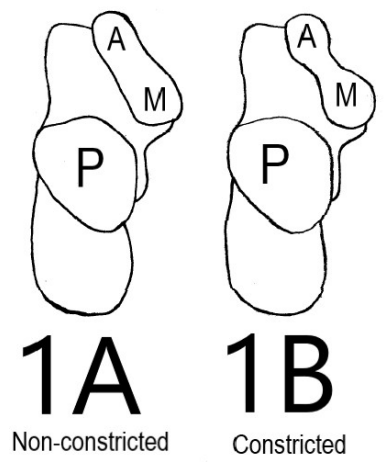

Fig. 2: Dorsal/superior calcaneus view of Type 1 specimens. $P=$ posterior facet, $M=$ middle facet, $A=$ anterior facet.

See Figure 2. In type 1 specimens the fused middle and anterior facets are non-constricted (1A) or constricted (1B).

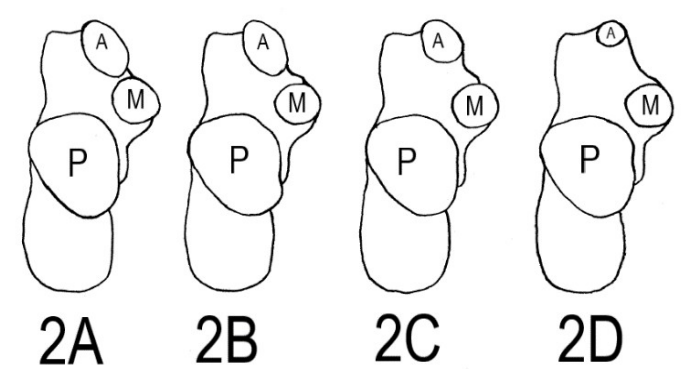

Fig. 3: Dorsal calcaneus, type 2 specimens. $P=$ posterior facet, $M=$ middle facet, $A=$ anterior facet. See text.
In type $2 \mathrm{~A}$ and $2 \mathrm{~B}$ (Figure 3 ): the middle and anterior facets are separated by $<2 \mathrm{~mm}$ and $2-5$ $\mathrm{mm}$, respectively, as defined by the lamsaard [1] classification. The current author defines $2 \mathrm{C}$ as the anterior and middle separation being greater than $5 \mathrm{~mm}$ up to $10 \mathrm{~mm}$. Further, when the anterior and middle facets are separated by $>10 \mathrm{~mm}$ this is defined as class $2 \mathrm{D}$.

A Literature Review Regarding Nomenclature. Currently in the literature there is no universal naming scheme that all authors utilize regarding calcaneal facet configuration. This lack of standardized nomenclature can promote significant confusion. In order to show the confusion possible in studying the calcaneal articular types, the following paragraph reviews the various names of just the calcaneal Type $1 \mathrm{~A}$ and $1 \mathrm{~B}$ facets given by different authors. Further, only 1 article, Jung [2] attempted to report the fused facet types with use of a measurable, metric method.

The 28 various authors reviewed in the English language who report on Type 1 calcanei and also distinguish the two fused subtypes ( $1 \mathrm{~A}$ and $1 \mathrm{~B}$ ) have used the following different wording to delineate the two subtypes (Table 1):

Names given by authors for Type 1A: notconstricted: 17 authors, plus the current author, use the term not (or un- or non) constricted [1,3-18]. To be accurate, the unconstricted nomenclature for type $1 \mathrm{~A}$ is synonymous with non-constricted or not constricted. Six authors use the words 'completely fused' or 'fused' in describing Type $1 \mathrm{~A}[2,19-23]$. 'No separation' are the words used by 2 authors $[24,25]$. Two authors $[26,27]$ used the term 'long continuous facet'. Yang [28] calls Type 1A specimens calabash-shaped. Names given For Type 1B: constricted: 17 authors [1,3-18], plus the current author, use the word constricted. Three authors use the words 'fused with notch or fused with narrowing' $[19,20,23]$. Two authors [21,22], use the words 'incomplete separation by a notch'. Two authors [24,25], use the words 'separation not complete'. Jung [2], used the wording 'partially connected'. Two authors [26,27] used 'figure 8' forms and Yang [28] used 'pear shaped'. For Table 1: NP=No photographs of sketches were submitted for fused FAM types. 
Table 1: Names given by authors for Type $1 \mathrm{~A}$ and Type 1B calcaneal configurations.

\begin{tabular}{|c|c|c|c|c|c|}
\hline bib\# & FAM articles & year & \# spec & FAM\% & names for $1 \mathrm{~A} / 1 \mathrm{~B}$ \\
\hline 4 & Agarwal & 2016 & 580 & $66.50 \%$ & unconst/constr \\
\hline 3 & Anjaneyulu & 2014 & 100 & $62.00 \%$ & unconst/constr \\
\hline 5 & Campos-Pel & 1989 & 176 & $53.40 \%$ & unconst/constr \\
\hline 6 & Gindha & 2015 & 325 & $69.50 \%$ & uncons/constr \\
\hline 7 & Gupta & 1977 & 401 & $66.80 \%$ & uncons/constr \\
\hline 1 & lamsaard & 2015 & 396 & $60.90 \%$ & uncons/constr \\
\hline 8 & Kori & 2016 & 600 & $73.70 \%$ & uncons/constr \\
\hline 9 & Kullar NP & 2015 & 200 & $72.50 \%$ & uncons/constr \\
\hline 10 & Kumar & 2017 & 200 & $54.00 \%$ & uncons/constr \\
\hline 11 & Laxmi & 2018 & 50 & $66.00 \%$ & uncons/constr \\
\hline 12 & Mini & 2012 & 50 & $74.00 \%$ & uncons/constr \\
\hline 13 & Parimala & 2016 & 88 & $60.20 \%$ & uncons/constr \\
\hline 14 & Patel/Patel & 2013 & 205 & $64.90 \%$ & uncons/constr \\
\hline & Present & 2019 & 158 & $31.60 \%$ & uncons/constr \\
\hline 15 & Sarvaiya & 2012 & 250 & $69.00 \%$ & uncons/constr \\
\hline 16 & Sharada & 2012 & 300 & $67.00 \%$ & uncons/constr \\
\hline 17 & Ukoha & 2017 & 220 & $63.20 \%$ & uncons/constr \\
\hline 18 & Uygur & 2009 & 221 & $58.40 \%$ & uncons/constr \\
\hline 28 & Yang & 2019 & 505 & $60.80 \%$ & pear shaped/calabash \\
\hline 24 & Boyan & 2016 & 57 & $61.40 \%$ & no separation/sep not complete \\
\hline 25 & Seema NP & 2012 & 300 & $56.00 \%$ & no separation/sep not complete \\
\hline 26 & Nemade & 2014 & 220 & $65.50 \%$ & long cont facet/trans fig 8 \\
\hline 27 & Drayer-Verhag & 1993 & 191 & $54.50 \%$ & long cont facet/fig 8 \\
\hline 2 & Jung & 2015 & 118 & $61.00 \%$ & fused/partially connected \\
\hline 23 & Shahabpour NP & 2011 & 49 & $53.10 \%$ & comp fusion/narrowing \\
\hline 21 & Jha & 1972 & 1600 & $59.50 \%$ & comp fusion/incomplsep by notch \\
\hline 22 & Nagar NP & 2012 & 529 & $76.40 \%$ & comp fusion/incomplsep by notch \\
\hline 19 & Anbumani & 2017 & 110 & $69.10 \%$ & comp fusion/fused w notch \\
\hline 20 & Barbaix NP & 2000 & 134 & $28.40 \%$ & comp fusion/fused w narrowing \\
\hline
\end{tabular}

$\mathrm{FAM}=$ fused anterior and middle calcaneal facets. $\mathrm{NP}=$ no photographs or sketches were submitted with the article.

As one can see, if there are too many different names used to delineate non-constricted versus constricted then it becomes challenging to accurately correlate the category types from author to author. Furthermore, 27 previous authors publishing in the English language studied by this author [1,3-28] have not defined how constricted the constriction must be in order for a specimen to be categorized as constricted versus non-constricted. This article reports 1 ) the number and types of calcaneal facets from 3 successive years at the anatomy lab, 2) the use of the calcaneal constriction index $(\mathrm{CCl})$ for measuring Type $1 \mathrm{~A}$ and $1 \mathrm{~B}$ types from the anatomy lab, and 3) the use of $\mathrm{CCl}$ to measure photographs/sketches from other authors in the literature.

\section{METHODS}

In May of 2006, 2007, 2008, three separate anatomical dissection studies of the subtalar joint were performed at Dr. William M. Scholl College of Podiatric Medicine at Rosalind Franklin University of Medicine and Science (SCPM) in North Chicago, Illinois, USA on 169 foot specimens. This study was performed using volunteer students, residents, and attending physicians. All specimens were either wet cadaver specimens or fresh frozen specimens. No dry bones were measured or reported. Race, sex, identities were not recorded. Photographs were taken of the superior surface of each of the calcanei, capturing the posterior and middle facets in all specimens and capturing anterior facets when present. Photographs of 158 calcaneal superior surfaces were deemed useable for purposes of this study. The calcaneal photographs were later used to measure and place each specimen in type $1 \mathrm{~A}$, $1 \mathrm{~B}$ (using the $\mathrm{CCl}$ method described below) or type 2A, 2B, 2C, 2D or type 3 categories. No Type 4 specimens were observed in either of the three 
years studied.

\section{Analysis of the photographs.}

When one assigns the Calcaneal specimens in the $2 A, 2 B, 2 C$, and $2 D$ subtypes, there is no real challenge, as they are placed into the subtypes based on only one metric measurement: the distance between the calcaneal anterior and middle facets (Figure 3). However, for the Type 1 specimens, when one attempts to place the specimens into constricted or non-constricted categories one finds that there is no clear constriction definition in the literature. Thus, one realizes that most of the previous authors have placed the specimens into the Type $1 \mathrm{~A}$ or $1 B$ subtypes using a rather subjective empirical method. An empirical method can be prone to error, as some researchers would have a more stringent requirement and other researchers would have a less stringent requirement regarding what is considered constricted. The one exception using a metric, rather than empirical definition is described in the Jung et al [2] article. The Jung method is recognized as a valid, definitive, metric measurement method but is deemed too cumbersome. Thus, the current author's calcaneal constriction index (CCl) was conceived and executed for the 50 fused types

(Types $1 \mathrm{~A}$ and $1 \mathrm{~B}$ ) out of the 158 total calcaneal specimens in the present study.

\section{The Calcaneal Constriction Index.}

The $\mathrm{CCl}$ measurement method is defined as follows for Type 1 calcanei, see Figure 4:

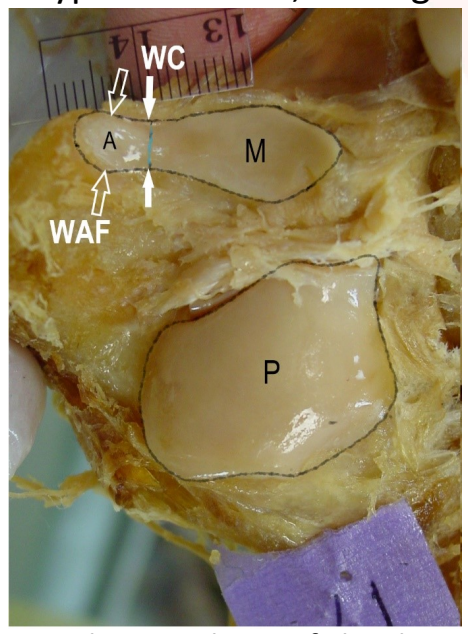

Fig. 4: SCPM cadaveric photo of the dorsal calcaneus. The small white arrows=the minimum width of the constriction (WC) between the middle (M) and anterior (A) facets. The large white arrows=the maximum width of the anterior facet (WAF). $P$ is the posterior facet. $\mathrm{WC} / \mathrm{WAF}=\mathrm{CCl}=0.83$
Measure the minimum width of the constriction (WC=smaller white arrows) between the anterior and middle facets, then measure the maximum width of the anterior facet (WAF=larger white arrows). The calcaneal constriction index (CCI) is simply the width of the constriction divided by the width of the anterior facet ( $\mathrm{CCl}=\mathrm{WC} / \mathrm{WAF})$. If an anatomic specimen's calcaneal constriction index measures 0.80 or greater, it is defined as non-constricted. If the $\mathrm{CCl}$ is less than 0.80 it is placed in the constricted category. This method of measurement can be performed directly in the cadaver lab or can also be done from photographs of the superior surface of the calcaneus. It is observed that the anterior facet is almost always smaller than the middle facet. It is also observed that the constriction between the anterior and middle facets is almost always smaller than the anterior facet. Indeed, in reporting the findings of the current cadaveric study, the constriction index was less than 1.0 in every Type 1 calcaneal specimen, meaning that the anterior facet width was always larger than the constriction between the middle and anterior facets.

The above $\mathrm{CCl}$ measurement method was performed on the 50 Type 1 specimens. Figure $5(\mathrm{Cl} \geq 80 \%)$ demonstrates four examples of specimens which are non-constricted, Type $1 \mathrm{~A}$.
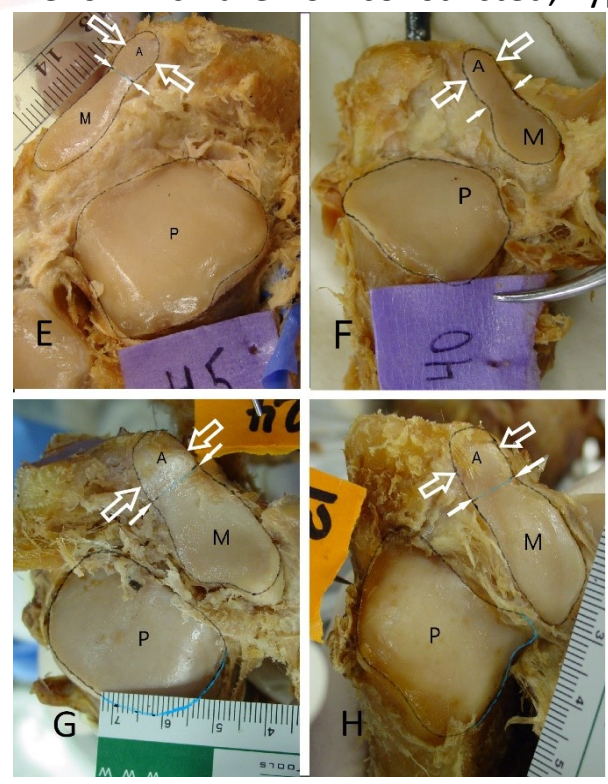

Fig. 5: Cadaveric calcanei from SCPM dissection. Four examples of Type $1 \mathrm{~A}$ non-constricted middle and anterior calcaneal facets. P, M, A are posterior, middle and anterior facets. Small arrows=width of the constriction and large arrows=width of the anterior facet. The $\mathrm{CCl}$ for $\mathrm{E}=0.80, \mathrm{~F}=0.83, \mathrm{G}=0.94$ and $\mathrm{H}=0.96$. 
Figure 6 shows four constricted specimens, where the $\mathrm{CCl}$ is less than $0.80(<80 \%)$, Type $1 \mathrm{~B}$.
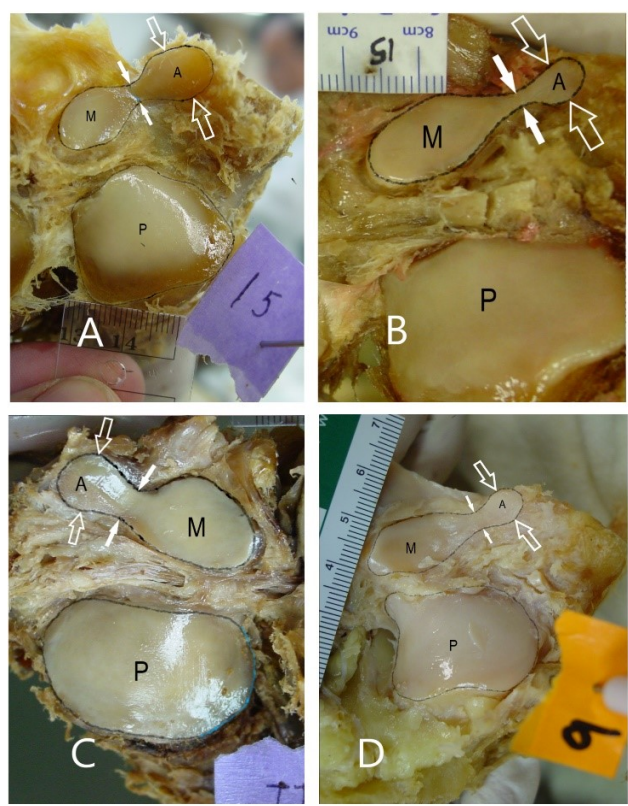

Fig. 6: Cadaveric calcanei from SCPM dissection. Four examples of Type 1B constricted middle and anterior facets. $P, M, A$ are posterior, middle and anterior facets. Small arrows=width of the constriction and large arrows=width of the anterior facet. The $\mathrm{CCl}$ for $\mathrm{A}=0.36$, $B=0.36, C=0.71$ and $D=0.64$.

\section{DISCUSSION}

Table 2: Calcaneal Constriction Index numbers of Type 1 specimens from photos of 24 articles.

\begin{tabular}{|c|c|c|c|c|c|c|}
\hline REF & Author & Year & Photo source & 1 A CCI & 1 B CCI & Error type \\
\hline 1 & lamsaard & 2015 & Fig 1 & $80 \%$ & $45 \%$ & sketch \\
\hline 3 & Anjaneyulu & 2014 & Fig 5,6 & $82 \%$ & $70 \%$ & wide ink \\
\hline 10 & Kumar & 2017 & Fig 2,3 & $82 \%$ & $50 \%$ & n/a \\
\hline 4 & Agarwal & 2016 & Fig 4 1A,B & $83 \%$ & $42 \%$ & n/a \\
\hline 13 & Parimala & 2016 & Fig 1 & $84 \%$ & $33 \%$ & wide ink \\
\hline 8 & Kori & 2016 & Fig 1,2 & $85 \%$ & $44 \%$ & n/a \\
\hline 16 & Sharada & 2012 & Fig 1: 1a, 1b & $86 \%$ & $57 \%$ & wide ink \\
\hline 26 & Nemade & 2014 & Fig 1, 2 & $87 \%$ & $45 \%$ & n/a \\
\hline 19 & Anbumani & 2017 & Fig 3,4 & $88 \%$ & $69 \%$ & n/a \\
\hline 7 & Gupta & 1977 & Fig 1, 2 & $88 \%$ & $57 \%$ & wide ink \\
\hline 14 & Patel/Patel & 2013 & Fig 1 & $88 \%$ & $56 \%$ & n/a \\
\hline 18 & Uygur & 2009 & Fig 3 B2,B1 & $89 \%$ & $60 \%$ & n/a \\
\hline 15 & Sarvaiya & 2012 & Fig 3 B2,B1 & $89 \%$ & $61 \%$ & blurry \\
\hline 27 & ayer-Verhag & 1993 & Fig 1 a, b & $90 \%$ & $42 \%$ & sketch \\
\hline 2 & Jung & 2015 & Fig 5: B,C & $90 \%$ & $55 \%$ & n/a \\
\hline 24 & Boyan & 2016 & Fig2 E,F & $90 \%$ & $49 \%$ & n/a \\
\hline 17 & Ukoha & 2017 & Fig 2: B, A & $90 \%$ & $61 \%$ & Wl, oblvw \\
\hline 12 & Mini Mol & 2012 & Fig 2: B1,B2 & $94 \%$ & $48 \%$ & n/a \\
\hline 18 & Uygur & 2009 & Fig 3: B2, B1 & $93 \%$ & $41 \%$ & B1 oblique \\
\hline 6 & Gindha & 2015 & Photo2 A,B & $95 \%$ & $60 \%$ & wide ink \\
\hline 11 & Laxmi & 2018 & Fig 3, Fig 2 & $96 \%$ & $89 \%$ & Wl, oblvw \\
\hline 21 & Jha & 1972 & Plate 2,3 & $100 \%$ & $58 \%$ & n/a \\
\hline 5 & Campos & 1989 & Fig 2: B2, B1 & $110 \%$ & $52 \%$ & sketch \\
\hline 28 & Yang & 2019 & Fig 2 l,IV & $110 \%$ & $44 \%$ & author tracing \\
\hline
\end{tabular}

Table 2 is listed in ascending order of the $1 \mathrm{~A}$ non-constricted column. The reasons for possible measurement error are in the error column. Photo source is the named location of the photo/sketch in each author's article.
Why $80 \%$ ? Application of the constriction index to photos and sketches in previous literature. Of the articles reviewed for this topic, 24 authors published sketches or photographs of examples of non-constricted and constricted fused anterior and middle facets. These authors are listed in Table 2.

The $\mathrm{CCl}$ for each author's photograph of Type 1 specimen was measured and calculated by the current author. The photographs/sketches of Type 1 specimens of Table 2 were enlarged as necessary by the current author in order to measure WC/WAF and calculate constriction indices for each of these photos/sketches. Possible errors in measuring photos of other authors: This author admits that some of the calcaneal surfaces are obscured or obliterated by lines drawn by the observed author delineating the articular surfaces, introducing possible error in measuring WC and WAF. Other possible errors include the photos not showing the facets well because of obliquity, or the photo is blurry. Additionally, error is possibly introduced because some of the examples are free-hand sketches. Regardless, Table 2 summarizes various calcaneal constriction index $(\mathrm{CCl})$ values for these photos/sketches of Type $1 \mathrm{~A}$ and $1 B$ specimens. The calcaneal constriction index measured from non-constricted photos varies from 0.80 to 1.10 with average $\mathrm{Cl}$ of $90 \%$. The $\mathrm{CCl}$ values for constricted photos/sketches vary from 0.33 to 0.70 with an outlier of 0.89 from the Laxmi [11] photo. This outlier is likely suspect because of the obliqueness of the photo in capturing the anterior facet and constriction. Even with the Laxmi [11] outlier, the average of all the Type 1B photos calculates to $53 \%$. Keep in mind that these measurements only reflect visual evidence of "good examples" of non-constricted and constricted samples chosen by each author and do not reflect the full variance in each author's Type $1 A$ and Type 1B specimens.

\section{CONCLUSION}

Summarizing for calcaneal Types 1, 2, 3 in the SCPM study reporting 158 specimens: There were 50/158 Type 1 specimens (32\%), 100/158 Type 2 specimens (63\%). There were eight Type 3 (5\%) specimens identified. Regarding 
the calcaneal constriction index: the $\mathrm{CCl}$ is shown to be simple, intuitive and easily executed by either direct lab measurement or from photos taken in the anatomy lab. The $\mathrm{CCl}$ applied to the photos/sketches of previous articles show nonconstricted values of 0.80 to 1.10 and constricted index values from 0.33 to 0.70 (less the outlier of 0.89 ). Thus, the $\mathrm{CCl} 80 \%$ threshold seems to be a valid demarcation for non-constricted versus constricted. It is shown in Table 1 that too many authors use too many naming schemes for describing calcaneal facet configuration. There needs to be a consensus established utilizing a single naming system for the dorsal calcaneal configurations. It is also hoped that future authors who are reporting findings for the types of calcaneal facets will be able to use a metric definition for both the non-constricted and constricted calcaneal specimens instead of an empiric definition for Type 1 specimens. The calcaneal constriction index is shown to be a pathway to complete one of these goals, as the $\mathrm{CCl}$ method is reproduceable between authors.

\section{ABBREVIATIONS}

$\mathrm{CCl}$ or $\mathrm{Cl}$ - Calcaneal Constriction Index

DPM - Doctor of Podiatric Medicine

FAM - Fused anterior and middle facets (Types $1 \mathrm{~A}$ and $1 \mathrm{~B}$ )

NP - No photographs/sketches of Type 1 were submitted (Table 1)

P, M, A - Posterior, Middle, Anterior calcaneal facets

SCPM - Dr. William M. Scholl College of Podiatric Medicine at Rosalind Franklin University of Medicine and Science

WAF - Width of the anterior facet (maximum width)

WC - Width of the constriction (minimum width)

\section{ACKNOWLEDGEMENTS}

Brad Ross, DPM. Private practice, Lincolnwood, Illinois, USA for providing oversight as attending physician at the SCPM dissection.

Bruce Manion, PhD Emeritus professor, Rosalind Franklin University of Medicine and Science, North Chicago, Illinois, USA, for coordinating the students and the dissection facility.

Dr. William M. Scholl College of Podiatric Medicine at Rosalind Franklin University of
Medicine and Science, North Chicago, Illinois, USA for allowing the use of their anatomy facilities for the students, residents and attendings. Funds for transportation, lodging, meals or other miscellaneous expenses for the project were provided by McShane Foot and Ankle, LLC, the employer of the author.

Illustrations were drawn by the author, Patrick McShane, DPM. The photographs were taken by the author and annotated by the author.

\section{Conflicts of Interests: None}

\section{REFERENCES}

[1]. lamsaard S, Uabundit N, Boonruangsri $P$, Sawatpanich T, Hipkaeo W. Types of facets on the superior articular surface of Isan-Thai dried calcanei. Int J Morphol, 2015;33(4):1549-1552. https:/ /doi.org/10.4067/S0717-95022015000400058

[2]. Jung MH, Choi BY, Lee, JY, Han CS, Lee JS, Yang YC, Cho BP. Types of subtalar joint facets. Surg. Radiol. Anat., 2015;37:629-638.

https://doi.org/10.1007/s00276-015-1472-1 PMid:25822134

[3]. Anjaneyulu K, Philips C, Tamang BK, Kumar A. Patterns of talar articulating facets in adult human calcanei from North-East India and their clinical correlation. Asian J of Medical Sciences 2014;5(4). https://doi.org/10.3126/ajms.v5i4.9486

[4]. Agarwal S, Garg S, Vasudeva N. Subtalar Joint Instability and Calcaneal Spurs Associated with the Configuration of the Articular Facets of Adult Human Calcaneum in Indian Population. J Clin Diagn Res 2016;10(9).

https://doi.org/10.7860/JCDR/2016/20216.8444

PMid:27790414 PMCid:PMC5071914

[5]. Campos FF, Pellico LG. Talar Articular Facets (Facies articulares talares) in Human Calcanei. Acta Anat 1989;134:124-127.

https://doi.org/10.1159/000146675 PMid:2718725

[6]. Gindha GS, Kaur H, Kaushal S, Singh M. Variations in the Articular Facets on Superior Surface of Calcaneus in North Indian Population: A Dry Bone Study. Human Biology Review, 2015;4(1):27-37.

[7]. Gupta SC, Gupta CD, Arora AK. Pattern of talar articular facets in Indian calcanei. J Anat 1977; 124(3):651-655.

[8]. Kori D, Prasad G, Rani A, Dewan RK, Singh R, Singh $P$. Study of variations in talar articular facets of human calcanei and their association with calcaneal spurs in North Indian population. Int J Anat Res, 2016;4(3):2710-16. https://doi.org/10.16965/ijar.2016.313

[9]. Kullar JS, Arora AK, Kapoor NS, Randhawa GK, Kullar KK. Morphology Of Talar Articular Facets Of Calcaneus And Its Clinical Implications, Kashmir J Med Sci. 2015;1(1):10-4. 
[10]. Kumar S, Singh AK, Fatima N, Akhtar NJ, Ratnesh R, Kumar V. A morphological study on patterns of human calcaneal articular facets for talus in population of Bihar and its clinical implications. J Evolution Med Dent Sci 2017:6(56):4193-96. https://doi.org/10.14260/Jemds/2017/908

[11]. Laxmi V, Mehra R, Sharma R. A MORPHOLOGICAL AND MORPHOMETRIC STUDY OF HUMAN CALCANEI AND THEIR ARTICULAR FACETS. Ind J Med Res and Pharm Sci 2018;5(2).

[12]. Mini MP, Silotry N, Haritha KN. Morphological study on patterns of talar articular facets of human calcanei. International J Med Clinical Research. 2012;3(3)136-139. https://doi.org/10.9735/0976-5530.3.3.136-139

[13]. Parimala NS, Devi DS, Reddy SM: A study of morphology and types of talar articular facets in adult human calcaneii of Andhra region. Int J Anat Res 2016;4(4):3209-14.

https://doi.org/10.16965/ijar.2016.440

[14]. Patel SJ, Patel RK, Chauhan KR, Bansal M. Patterns of talar articular facets on calcaneum and its clinical implication. Int J Anat Physiol. 2013;2(4):023026.

[15]. Sarvaiya, B. J.; Patel, S. V.; Single, G. \& Master, D. C. The types of talar articular facets and morphometric measurements of the human calcaneum bone of Gujarat Region. Nat. J. Integr. Res. Med., 2012;3(3):34-8.

[16]. Sharada R, Sneha K, Gupta C, Pai SR and Rairam GB. Non metrical study of the pattern of talar articular facets in south Indian dry calcanei. Surg Radiol Anat 2012; 34:487-491.

https://doi.org/10.1007/s00276-012-0939-6

PMid:22327639

[17]. Ukoha U, Feechukwu O, Onuoha C. Study of the morphologic and morphometric patterns of talar articular facets on dry adult calcaneal bones in SouthEastern Nigerian population. Revista Argentina Anatomia Online 2017;8(1):29-39.

[18]. Uygur M, Atamaz F, Celik S, Pinar Y. The types of talar articular facets and morphometric measurements of the human calcaneus bone on Turkish race. Arch Orthop Trauma Surg 2009;129:909-914. https://doi.org/10.1007/s00402-008-0729-0 PMid:18810474

[19]. Anbumani TL, Sridharan R, Thamarai Selvi A: An Anatomical Study of Morphology and Morphometric Analysis of Calcaneum and Its Talar Articular Surfaces. Int J Anat Res. 2017; 5 (3.2):4223-29.

https://doi.org/10.16965/ijar.2017.291
[20]. Barbaix E, Van Roy P, Clarys JP: Variations of anatomical elements contributing to subtalar joint stability: intrinsic risk factors for post-traumatic lateral instability of the ankle? Ergonomics 2000;43(10):1718.

https://doi.org/10.1080/001401300750004122 PMid:11083150

[21]. Jha MR, Singh DR. Variations in the articular facets on the superior surface of calcaneus. J.Anat. Soc. India. 1972;21(1);40-44.

[22]. Nagar SK, Malukar Ojaswini, Kubavat Dharati, Gosai SR, Andani RH, Patel Bhaskar. TYPES OF TALAR ARTICULAR FACETS AND MORPHOMETRIC MEASUREMENTS OF THE HUMAN CALCANEUS BONE. National J of Medical Research 2012;2(2):128-132.

[23]. Shahabpour M, Deville A, Van Roy P, Vaes P, DeMey J, De Maeseneer M: Magnetic Resonance Imaging of anatomical variants of the subtalar joint. Surg Radiol Anat 2011;33: 623-630.

https://doi.org/10.1007/s00276-011-0788-8 PMid:21340734

[24]. Boyan N, Ozsahin E, Kizilkanat E, Soames R, Oguz O: Morphometric Measurement and Types of Articular Facets on the Talus and Calcaneus in an Anatolian Population. Int J Morphol 2016;34(4):1378-1385. https://doi.org/10.4067/S0717-95022016000400033

[25]. Seema, Singh M, Mahajan A, Gandhi DK. The Variations in Calcaneal Articular Facets in North Indian Population and its Clinical Implication. GJMEDPH, 2012;1(1).

[26]. Nemade KS, Meshram MM, Kasote AP, Kamdi NY. ARTHRITIS OF THE SUBTALAR JOINT ASSOCIATED WITH SUSTENTACULUM TALI FACET CONFIGURATION. Int J Anat Res. 2014;2(4). https://doi.org/10.16965/ijar.2014.525

[27]. Drayer-Verhagen F. Arthritis of the subtalar joint associated with sustentaculum tali facet configuration. J Anat. 1993;183:631-634.

[28]. Yang Y, Cheng H, Xiong Z et al. Classification and Morphological Parameters of the Calcaneal Talar Facet: Which Type Is More Likely to Cause Osteoarthritis in Chinese Population? BioMed Res Int Vol 2019. https://doi.org/10.1155/2019/6095315 PMid:31080826 PMCid:PMC6475557

How to cite this article:

Patrick Anderson McShane. CALCANEAL ARTICULAR FACET CONFIGURATION TYPES: A REPORT OF A CADAVERIC STUDY AND THE CALCANEAL CONSTRICTION INDEX. Int J Anat Res 2020;8(3.3):7715-7721. DOI: 10.16965/ ijar.2020.199 